\title{
An organizer controls the development of the "sword," a sexually selected trait in swordtail fish
}

\author{
Cornelius Eibner, ${ }^{1}$ Silke Pittlik, Axel Meyer, and Gerrit Begemann* \\ Chair for Zoology \& Evolutionary Biology, Department of Biology, University of Konstanz, 78457 Konstanz, Germany \\ *Author for correspondence (email: gerrit.begemann@uni-konstanz.de) \\ ${ }^{1}$ Present address: Department of Zoology, National University of Ireland Galway, Galway, Ireland.
}

SUMMARY Male swordtail fish of the genus Xiphophorus (Poeciliidae) possess a "sword" that is composed of several colored elongated ventral fin rays of the caudal fin. The sword is a secondary sexual trait that evolved through sexual selection by female preference. To uncover the developmental mechanisms underlying the metamorphosis from a juvenile caudal fin to the sword, we have devised a transplantation protocol to assay the fate of single transplanted fin rays and their interactions with flanking rays. These experiments provide evidence for the existence of a previously unrecognized inductive signal that originates in those rays that develop into the two longest sword rays. This "sword organizer" causes adjacent fin rays to grow and become integrated into the sword and induces the development of an additional, typically pigmented sword in grafts to the dorsal part of the caudal fin. We show that the potential to develop a sword is restricted to certain parts of the caudal fin. Our findings suggest that the evolution of swords in swordtails required the acquisition of two developmental mechanisms: the establishment of signaling competence in prospective sword rays in the embryo or early larva, and its activation through androgen signaling in adult male fish.

\section{INTRODUCTION}

The genus Xiphophorus (Poeciliidae) consists of 26 species (Kallman and Kazianis 2006) that are divided into species with swords, the swordtails, and the typically sword-less platyfishes. In adult swordtail males a set of ventral fin rays of the caudal fin are elongated and often ornamented with bright, contrasting pigmentation, forming the so-called sword (for definitions of which traits constitute a sword, see Basolo 1991; Wiens and Morris 1996; Meyer 1997). Males of platyfish, however, never develop swords, although the most parsimonious reconstruction of sword evolution, based on molecular phylogenies, suggests that some species of platyfish might have secondarily lost the ability to express swords. However, the evolutionary history of this trait within the genus remains debated (Basolo 1991; Meyer et al. 1994, 2006; Meyer 1997).

The sword is a classical example of a sexually selected trait that was already recognized as such by Charles Darwin (Darwin 1871). Swords have a selective advantage through sexual selection, as females prefer larger swords over shorter ones (Basolo 1990a). However, there is also cost in terms of natural selection (Meyer et al. 1994), because swords reduce swimming performance (Basolo and Alcaraz 2003) and swords are not only attractive to females, but also to predators (Rosenthal et al. 2001). Female preference for males with a conspicuous sword ornament probably predates the appearance of these structures in males. This has been suggested by experiments in which females from different platy species were shown to prefer conspecific males with artificially attached swords (Basolo 1990b, 1995a) and sworded males of other species over males of their own species. Moreover, female Priapella olmecae, of the swordless sister group Priapella, also prefer males with artificial swords (Basolo 1995b). These experiments suggest that the male trait might have evolved in response to a pre-existing female bias (Kirkpatrick and Ryan 1991; Endler 1992), such as a general preference for the apparent size of potential mates rather than for the sword itself (Rosenthal and Evans 1998).

Juvenile male swordtails are initially swordless, but a sustained increase of testosterone levels during sexual maturation has been shown to be sufficient to initiate sword development. Intriguingly, exogenous addition of testosterone can also induce swords in swordtail females, in juvenile males, and in some normally swordless platy species (Gordon et al. 1943; Cohen 1946; Dzwillo 1962, 1964; Zander and Dzwillo 1969). Therefore the genetic developmental architecture required for producing the sword seems to be present more basally within the genus, and at least in some platy species a dormant process of sword formation can be initiated in the laboratory. This developmental evidence agrees with the emergence of the sword within the genus, which suggested that the ability to 
express swords arose early in the genus and was lost secondarily (Meyer et al. 1994).

The evolution of the sword must have required changes in the molecular pathways that regulate the growth and coloration of parts of the caudal fin. Hybridization experiments between platy fish and swordtails suggested the existence of several genes that are required for the development of the sword. These were collectively termed "sword genes" ("Schwertgene") (Zander and Dzwillo 1969). In platy fish, some sword gene activity might have become latent secondarily, because an exogenous supply of testosterone causes the outgrowth of a small sword-like ventral caudal fin extension in several species (Zander and Dzwillo 1969). Furthermore, in hybrids between platy fish and swordtails, the swordtail genome contributes alleles of genes that allow a sword to develop. The observed variation in sword size in different hybrid combinations suggests that several genetically unlinked sword genes may exist (Zander and Dzwillo 1969).

The molecular mechanisms governing Xiphophorus sword formation are largely unknown. Much of what is known about fin development has been inferred from studies on regenerating fins in the zebrafish, Danio rerio (Akimenko et al. 2003). Initial efforts to identify sword-specific genes relied on analyzing the expression profiles of candidate genes known to be involved in zebrafish fin regeneration. Using this approach, the muscle segment homeobox gene $C(m s x C)$ was shown to be up-regulated in developing sword rays of the green swordtail, Xiphophorus helleri, and in Xiphophorus montezumae (Zauner et al. 2003). Moreover, the gene was also found to be expressed in the anal fin of maturing males, which is transformed from a normal fin with a set of typical fin rays into an intromittent, sperm-transferring organ with individually different ray shapes, termed the gonopodium. Just like the sword, the gonopodium develops during the males' sexual maturation under the influence of endogenous androgens, through the growth of three anterior fin rays, the " $3-4-5$ " complex, and its differentiation into terminal bony ray segments specialized for internal fertilization (Langer 1913; Gordon and Rosen 1951).

To better understand how the sword might have been gained during evolution, we investigated the nature of the mechanisms that govern the metamorphosis of the juvenile caudal fin into the adult-sworded form in the Green Swordtail $X$. helleri (Fig. 1A). Two models could explain the observed pattern of sword ray growth and differentiation. In the first, an unknown signaling activity might exist in all sword rays at sufficient concentrations to cause autonomous sword ray outgrowth, but it is absent or present at insufficient levels in other parts of the caudal fin (Fig. 1B). In the second model, one or more sword rays may be the source of the signaling activity, which is relayed to neighboring fin rays, to induce growth and sword development (Fig. 1C). In order to test which of these hypotheses most closely match the actual mechanisms of sword development, we performed a series of autologous transplantations (within the same animal) as well as fin extractions to expose sword- and nonsword ray tissue to ectopic positions within regenerating caudal fin tissue. Together, these experiments allowed us to locate the position of swordinducing signaling centers.

\section{MATERIALS AND METHODS}

\section{Fish stocks and maintenance}

$X$. helleri were kept in planted aquaria at $25^{\circ} \mathrm{C}$ and a $12 \mathrm{~h} \mathrm{light} / 12 \mathrm{~h}$ dark cycle. Fish were taken from stocks kept at the University of Konstanz. For all manipulations of adult animals, fish were anesthetized in $0.16 \mathrm{mg} / \mathrm{ml}$ Tricaine solution (Sigma, Aldrich, Steinheim, Germany) and allowed to recover in system water.

\section{Fin ray transplantation}

Transplantations were carried out both in adult males and in juvenile fish that did not yet exhibit adult characters, such as gonopodium, sword, or gravidity spot. First, one fin ray was removed at the host site by excising the dorsal and ventral interray tissue and the proximal-most end of the fin ray with a razor blade. This step opened up a gap, the host site, that was allowed to regenerate for 24 or $48 \mathrm{~h}$. A fragment of four to five segments from the proximal part of the donor fin ray was then excised from the same fish. Using a razor blade, a hole was introduced into the epidermis underneath the regenerating tissue at the host site and the donor fragment was inserted into the host site by pushing it under the epidermis and into the muscle tissue. After 24 or $48 \mathrm{~h}$, all caudal fin rays were amputated at the level of the distal segments of the transplanted material to allow a homogenous regeneration of the whole fin. Regenerated fins bear one additional fin ray, due to the regeneration of both the transplanted ray and the stump of the donor ray. In some cases, the grafted ray and the stump tissue fused at the proximal end of the graft, so that the regenerating fin ray replaced the original ray in its position.

\section{Fin ray extirpation}

Fin rays were fully removed by an incision close to the base of the fin and by cuts along the interray tissue. Regenerating stumps were recut at weekly intervals. In rare cases ray regeneration failed and the extirpation was permanent, with no requirement to recut the ray.

\section{Testosterone treatments}

Juvenile $X$. helleri were exposed every 3-4 days to $10 \mu \mathrm{g}$ of 17-methyl-testosterone (Sigma Aldrich) per 11 aquarium water, made from a $10 \mathrm{mg} / \mathrm{ml}$ stock in ethanol. For the duration of the experiment, fish were kept in 301 tanks without vegetation.

\section{Photography}

Anesthetized fish were placed on a glass slide and the fin was positioned under a coverslip with a small amount of water. Images were taken on a Zeiss Axiophot microscope, using a digital camera (AxioCam MRc, Carl Zeiss MicroImaging $\mathrm{GmbH}$, Göttingen, Germany), and were processed using Zeiss Axiovision and Adobe Photoshop software. 

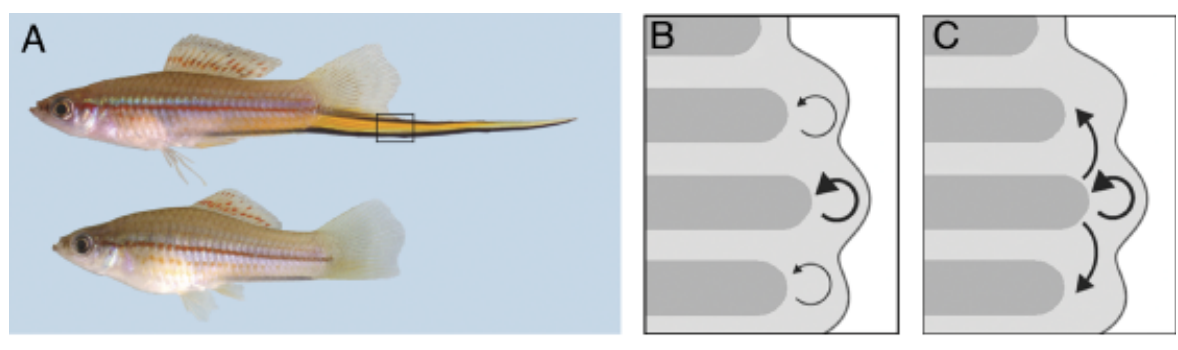

D

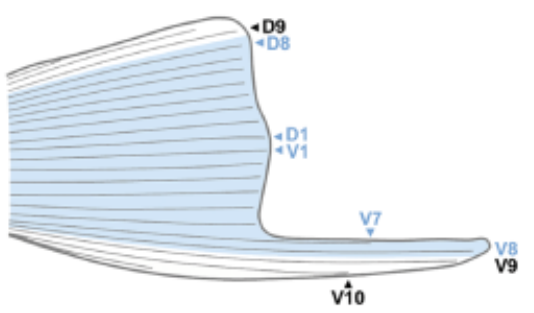

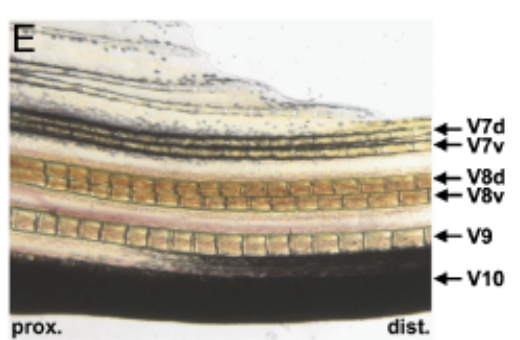

Fig. 1. Anatomy of the sword and possible models for the regulation of sword ray growth in swordtail fish. (A) Adult male (above) and female of the Green Swordtail, Xiphophorus helleri; frame indicates the region of a younger sword shown in E. (BC) Two models of sword growth; (B) Growth is an inherent autonomus trait of all rays that form the sword; growth rates are determined by the strength of as yet unidentified signals. (C) Single sword rays produce signals that stimulate their own growth and that induce growth in flanking sword-rays (in a combination of autonomously and nonautonomously acting mechanisms). Three fin rays (dark areas) are shown that grow to form the sword. (D) Schematic depiction of a growing adult male caudal fin, indicating branched and unbranched rays (underlaid in blue and white, respectively); dorsal (D) and ventral (V) fin rays are numbered from the caudal fin midline toward the periphery; only 22 fin rays are shown for simplicity. (E) The sword comprises the segmented branched rays V7 and V8 (dorsal and ventral branches are indicated) and the segmented unbranched rays V9 and V10. The sword is bordered by melanophores that accumulate around the rays of V7 and along the ventral caudal fin rays.

\section{RESULTS}

\section{Anatomy of the sword in $X$. helleri}

The caudal fin of the green swordtail $X$. heller $i$ is comprised of typically 15 dorsal (D) and 15 ventral (V) skeletal fin rays (lepidotrichia) each (Fig. 1, A and D). For ease of description, in the following we identify individual rays according to their distance from the equatorial line (after Dzwillo 1964). In this system, D8-V8 comprise the segmented branched caudal fin rays; they are flanked by up to seven segmented unbranched rays, all of which, with the exception of D9/V9, are significantly shorter than the remaining rays in females and juveniles. This mirror symmetry along the equatorial axis is broken at the onset of sword development in juvenile males (Fig. 1D), when the caudal fin switches from an isometric mode of growth, in which the long fin rays grow at a constant rate, to an allometric mode, in which sword rays grow at faster rates than the remaining fin. The length of the mature sword is comprised of four fin rays: The pigmented, branched fin ray V7, which forms the black margin of the sword's dorsal aspect, the yellow-reddish colored, branched fin ray $\mathrm{V} 8$, the yellow-colored, unbranched fin ray V9, and the black pigmented, unbranched fin ray $\mathrm{V} 10$, whose pigmentation is continuous with that of the short marginal rays V11-V15 and the ventral black pigment stripe of the caudal trunk (Fig. 1, D and E). Rays V8-10 develop significantly thicker lepidotrichs upon sword development. Rays V8 and V9 are the longest sword rays, with V8 being slightly longer than V9 (Dzwillo 1964). The result is a yellow-reddish colored sword, highlighted by bordering black pigment stripes.
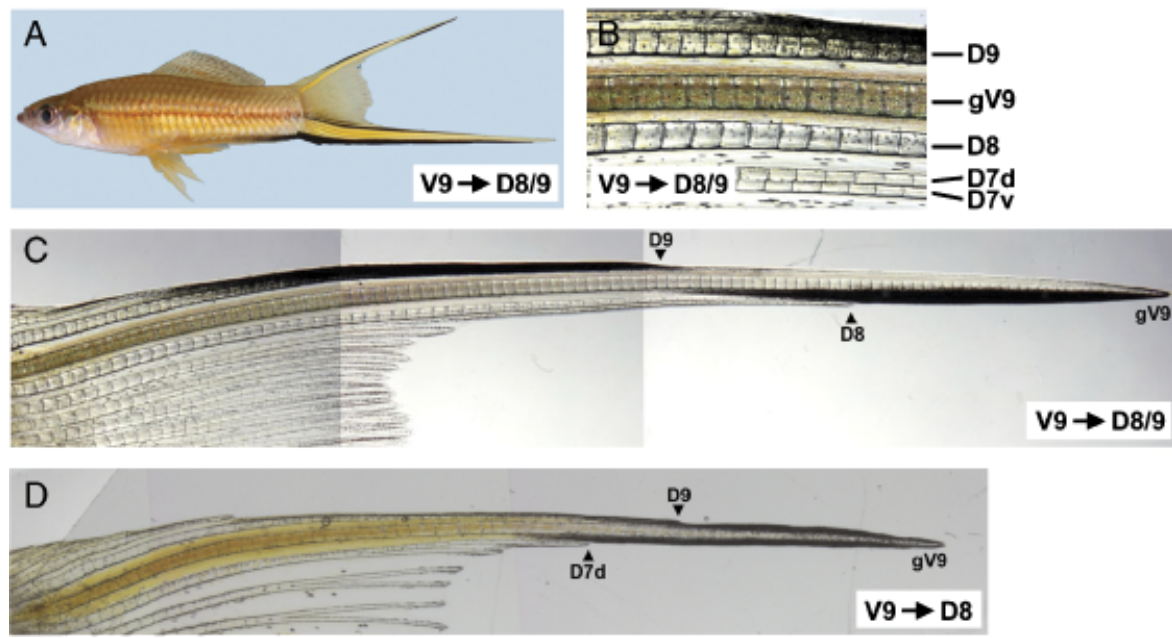

Fig. 2. Autotransplantation of sword ray V9 induces an ectopic sword within the caudal fin. (A-D) Adult fins after transplantation and regeneration, 3 months after ray V9 was grafted (gV9) into the dorsal caudal fin between D8 and D9 (A-C), or replacing D8, 1 year after the grafting procedure (D). (A) Adult male in which V9 induced the regeneration of an ectopic sword; (B, C) detail of ectopic sword; ectopic melanophores appear in interray tissue between the graft and D8, and cover the distal area of D9; (D) a graft of V9 replacing endogenous ray D8; only the dorsal branch of the flanking ray (D7d) has been induced to grow excessively. 


\section{A single sword ray induces an ectopic sword when transplanted dorsally}

In order to test the hypothesis that sword rays organize sword development in a nonautonomous fashion (Fig. 1C), we transplanted individual sword rays into ectopic positions within the caudal fin of the same animal. Certain sub-species of $X$. helleri develop an unpigmented small dorsal fin ray extension when treated with testosterone, suggesting that both the ventral and dorsal portions of the caudal fin may be competent to form a sword (Dzwillo 1962, 1964). Transplantation of V9 into the corresponding dorsal position, i.e., the interray region between D8 and D9, led to transplant regeneration according to its original position $(n=9)$, in which the regenerated V9 retained its yellow xanthophore-based pigmentation and regenerated thick lepidotrichs (Fig. 2, A and B).

Transplanted V9 sword rays ultimately grew beyond the normal length of dorsal caudal rays, and induced the regenerative development of an additional, ectopic sword that nearly reached the length of the genuine sword and matched its pigmentation (Figs. 2, C and D and 3, A, B, and F). In this ectopic sword, V9 is the longest ray and the flanking rays D8 and D9 regenerated beyond their usual length by developing additional lepidotrich segments (Fig. 2C). Moreover, black melanophore-derived pigmentation, typical for the sword, formed on the distal lepidotrich segments of ray D9, in the interray region between the transplant and its ventral neighbor ray, and on the distal tips of the grafted ray itself (Fig. 2, $\mathrm{C}$ and D). To examine if sword-organizing activity is restricted to ray $\mathrm{V} 9$, we transplanted ray $\mathrm{V} 8$ into the same dorsal position. Grafts of V8 retained their pigmentation pattern of yellow xanthophores in the ectopic dorsal position and overgrew the flanking rays $(n=3)$ (Fig. 3, C-E). In all cases induction of growth beyond the length typical for the dorsal caudal fin was observed in adjacent rays, particularly in the dorsal branch of flanking rays (Fig. 3, D and E).

We conclude that sword-inducing signals are carried by both long sword rays, V8 and V9. When transplanted into a dorsal caudal fin position, both rays regenerate according to their origin with respect to size and pigmentation and induce increased growth in flanking fin rays. They differ, however, in their ability to trigger the development of strong black pigmentation in flanking rays and interray tissue.

\section{Sword ray melanophores do not spread into nonsword tissue}

In comparison with rays V8 and V9, sword ray V7 is somewhat shorter and more heavily pigmented by melanophores. The assumption that V7 does not contribute autonomously to the growing sword and instead responds to putative swordorganizing signals is supported by the fact that its segmented branch adjacent to V8 typically exceeds the length of its dorsal sister branch (Fig. 3F). To test if coloration and growth are traits inherent of $\mathrm{V7}$, we examined regeneration of $\mathrm{V7}$ in an ectopic position between rays D8 and D9. When V7 is transplanted to a dorsal position it does not regenerate to its former length, but grows to the same length as adjacent rays D8 and D9 $(n=5)$ (Fig. 3, G and H). D8 and D9 are not induced to transform into sword rays, even after several weeks following a successful grafting procedure. The V7 graft maintains a melanophore pattern that is restricted to the regenerated tissue of the transplant and the adjoining interray tissue. Thus V7 maintains its coloration in an ectopic position, but lacks the ability to regenerate to its former length or to induce exaggerated growth in neighboring tissue. This suggests that growth of V7, in its normal position in the sword, is controlled by signals from adjacent rays V8 and V9. The V7 pigment pattern, in contrast, is ray-autonomously maintained during regeneration and does not induce similar coloration patterns in the flanking fin rays.

\section{Fin rays acquire sword-fate before sexual maturation}

The dorsal grafts showed that rays V8 and V9 are capable of inducing sword fates in flanking fin rays. To test directly if this organizing activity is a trait inherent to V8 and V9 before endogenous testosterone signaling, or if it is acquired concomitantly to sexual maturation, we performed transplantations of V9 to a dorsal position in the caudal fin of juvenile fish that did not show signs of beginning sexual maturation, and then induced male-like maturation with testosterone treatment. Transplants of V9 dorsally between D8 and D9 of juveniles were treated with exogenous testosterone 3 days after successful grafting $(n=5)$, and assayed 2 months later. All grafts had experienced sustained growth and induced growth in flanking rays. By this time, two grafts had induced black pigmentation in flanking tissue (Fig. 3, I and J). As controls, we performed identical grafts of $\mathrm{V} 9$ in juveniles that had been exposed to testosterone for 10 days before transplantation. In all cases $(n=5)$, regenerates formed ectopic swords with strong black pigmentation at the tip of the graft and in flanking dorsal tissue, similar to ectopic swords induced in adult fish (Fig. 1, A-D and not shown). These results support the notion that ventral fin rays in juvenile $X$. helleri are already competent to form sword rays, before maturation and independent of the animal's eventual sexual differentiation.

\section{Sword development is critically dependent on sword rays V8 and V9}

Given that the presence of the sword rays V8 and V9 is sufficient to induce characters associated with sword development in flanking rays, we examined whether these rays are required to induce a normal sword. We excised complete fin rays from the base of the caudal fin in sexually undifferentiated juvenile 

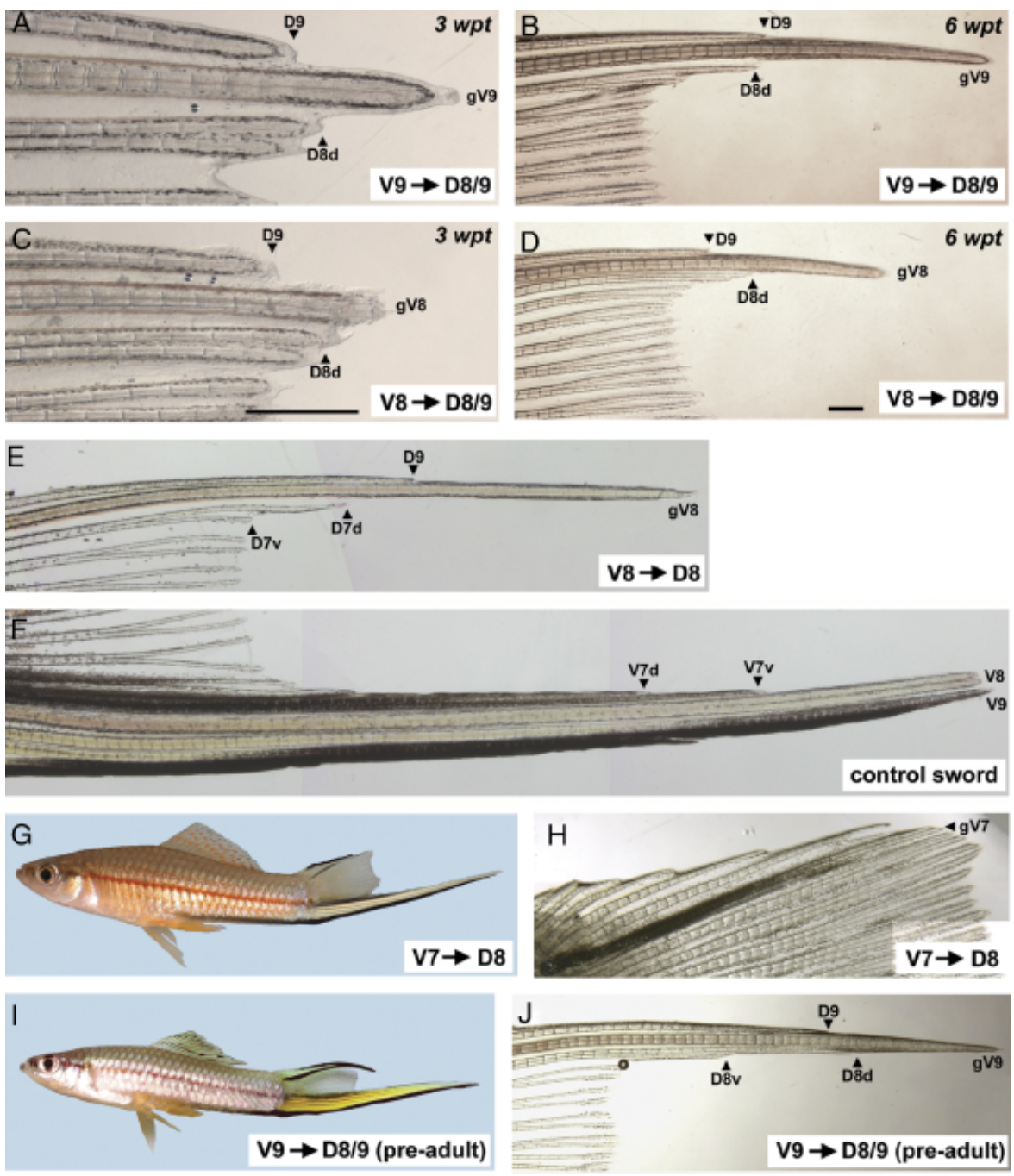

Fig. 3. Autotransplantation of sword rays within the caudal fin. (A-D) Grafts of $\mathrm{V} 9(\mathrm{~A}, \mathrm{~B})$ and of $\mathrm{V} 8(\mathrm{C}, \mathrm{D})$ into the dorsal caudal fin between D8 and D9 at three $(\mathrm{A}, \mathrm{C})$ and six $(\mathrm{B}, \mathrm{D})$ weeks posttransplantation (wpt). Scale bars $=1 \mathrm{~mm}$. (E) Graft of V8 (gV8) replacing D8; 12 months after transplantation, the dorsal branch of the flanking ray (D7d) has been induced to grow excessively; ectopic melanophores are not observed with grafts of V8 (E). (F) The regenerated genuine sword of the fish shown in (E) at the same magnification, displaying the pigmentation pattern of the sword and the unequal lengths of the dorsal (V7d) and ventral $(\mathrm{V} 7 \mathrm{v})$ branches of ray V7. Note that V8 is weakly pigmented by melanophores in its interray mesenchyme, whereas the rays of V7 are covered completely, and those of V9 and V10 are covered distally with melanophores. (G, H) Grafts of V7 (gV7) into the dorsal caudal fin 3 months after transplantation. $\mathrm{gV7}$ does not induce growth in flanking rays $(\mathrm{G}, \mathrm{H})$; melanophores are restricted to the grafted ray $(\mathrm{H})$; a black pigment stripe on the dorsal margin of the caudal fin, as seen in $(G)$, occasionally also appears in unoperated matured males of Xiphophorus helleri. (I, J) A graft of V9 (gV9) to the dorsal caudal fin performed in an immature animal, followed by regeneration while exposed to testosterone for 3 months (I); gV9 recruits D8 and D9 into an ectopic sword $(\mathbf{J})$. Note the black pigmentation at the dorsal margin and distal tip of the ectopic sword (I, J). fish, either V9 alone or in combination with V8. Testosterone was added immediately following ray extraction to induce sword development. Fin ray growth was measured in the remaining sword rays 5 weeks later, when, as an internal control of the response to the treatment, gonopodium development in all fish was well advanced as a sign of sexual maturation.

When compared with control fish, extraction of V9 alone did not inhibit the sword-like growth response in the remaining rays (Fig. 4, A, B, and $\mathrm{C}^{\prime}$ ). However, the length and segment number of flanking rays V8, and especially V10, was significantly reduced (Fig. 4A; Tables 1 and 2). Extraction of both V8 and V9, on the other hand, inhibited the normal growth characteristics of the remaining sword rays (Fig. 4, A, $\mathrm{D}$, and $\left.\mathrm{D}^{\prime}\right)$, resulting in a small overgrowth of $\mathrm{V7}$ that is also observed in the ventral caudal fin of female fish and immature males (Fig. 1A). While in normal swords the ventral branch of the bifurcating ray $\mathrm{V} 7$ is on average four to five segments longer than the dorsal one, removal of V8 and V9 results in an equal growth rate within both branches of V7 (Fig. 4A). In addition, growth of V10 is slowed down considerably in the absence of V9, whereas V10 does not respond at all to testosterone when both V8 and V9 are missing (Fig. 4A). In both extraction situations, the melanophore-based pigmentation that covers V7 and V10 was present (Fig. 4, C and D), despite an overall inhibition of sword growth.

These observations suggest that growth and pigmentation of sword rays are independent characters and show that rays V8 and V9 affect the growth of their immediate neighbors, V7 and V10. Furthermore, the effects on segmental addition in V7 and V10 are exacerbated by simultaneous removal of V8 and V9, suggesting that these rays act synergistically in promoting the growth of adjacent fin rays.

\section{Transplanted nonsword rays regenerate according to their new position within the sword}

To test if nonsword rays are incorporated into the sword, we transplanted fin ray D9 adjacent to V9 into the sword $(n=2)$. 

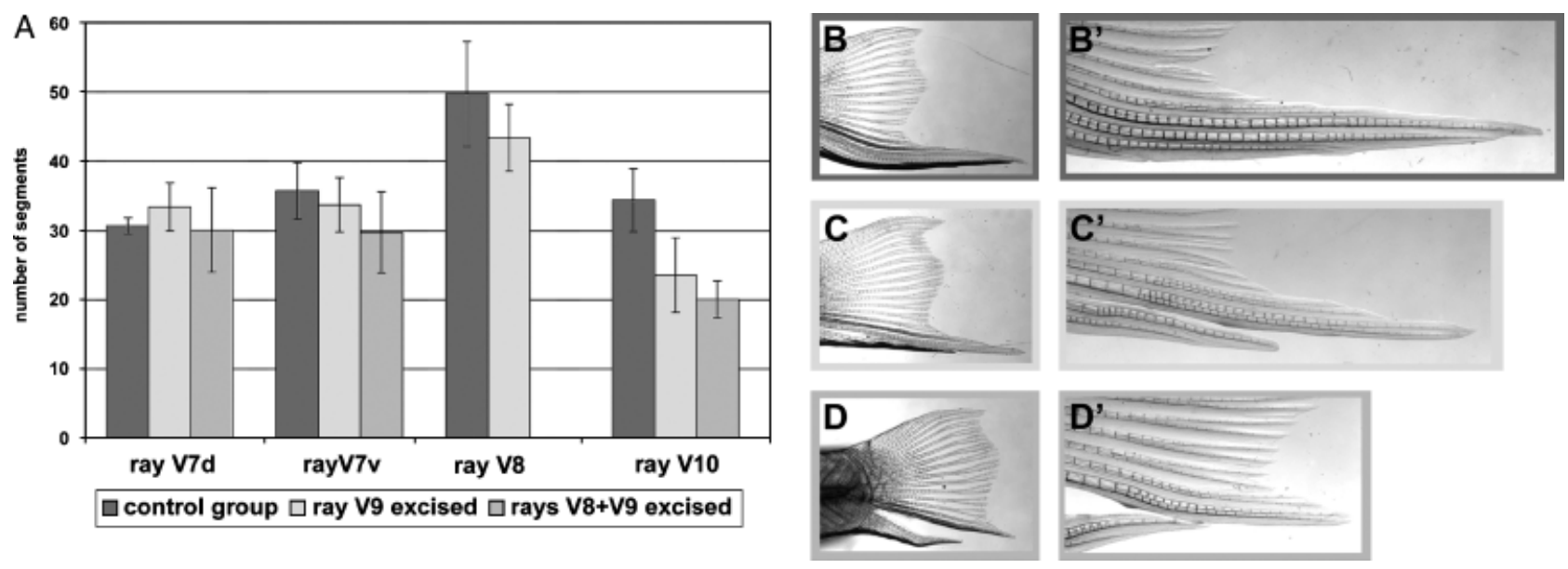

Fig. 4. Sword development in the absence of ray V9, or rays V8 and V9. (A) The number of segments of sword rays V7 (dorsal and ventral branches), V8 and V10 was counted 5 weeks after the beginning of testosterone treatment in controls $(n=3)$, and in fish in which V9 ( $n=6)$, and V8 together with V9 $(n=4)$ had been excised. Vertical lines indicate standard deviations. (B-D') Sword development 5 weeks after testosterone induction in wildtypes $\left(\mathrm{B}, \mathrm{B}^{\prime}\right)$ and following excision of $\mathrm{V} 9\left(\mathrm{C}, \mathrm{C}^{\prime}\right)$ and $\mathrm{V} 8$ and V9 (D, $\left.\mathrm{D}^{\prime}\right)$; fin rays before (B, C, D) and after they have been bleached for counting segments $\left(\mathrm{B}^{\prime}, \mathrm{C}^{\prime}, \mathrm{D}^{\prime}\right)$.

The grafted rays integrated into the host tissue, grew out further than the D9-regenerate at the donor site, and matched the length of neighboring sword rays (Fig. 5, A and B). A reduction in the regenerates' thickness has frequently been observed in zebrafish ray transplants (Zauner et al. 2003), and

Table 1. Length of sword rays ( $\mathrm{mm})$ of juvenile fish after 5 weeks of testosterone treatment in the absence of ray $\mathrm{V8}$, or rays $\mathrm{V8}$ and $\mathrm{V} 9$

\begin{tabular}{|c|c|c|c|c|}
\hline & Ray V7d & Ray V7v & Ray V8 & Ray V10 \\
\hline Control $1^{1}$ & 10.5 & 12 & 15.5 & 11 \\
\hline Control $2^{1}$ & 11.5 & 13.5 & 18 & 12.5 \\
\hline Control $3^{1}$ & 10 & 11 & 14.5 & 13.5 \\
\hline Mean & 10.67 & 12.17 & 16.00 & 12.33 \\
\hline Standard deviation & 0.76 & 1.26 & 1.80 & 1.26 \\
\hline $\mathrm{V} 9-1^{2}$ & 10 & 11 & 13 & 9 \\
\hline$V 9-2^{2}$ & 11 & 12 & 13.5 & 7 \\
\hline V9- $3^{2}$ & 10.5 & 11.5 & 12 & 6.5 \\
\hline V9-4 $4^{2}$ & 11 & 12 & 14 & 6.5 \\
\hline V9-5 $5^{2}$ & 10 & 11.5 & 13.5 & 8 \\
\hline V9- $6^{2}$ & 12 & 13 & 15 & 9 \\
\hline Mean & 10.75 & 11.83 & 13.50 & 7.67 \\
\hline Standard deviation & 0.76 & 0.68 & 1.00 & 1.17 \\
\hline $\mathrm{V} 8+\mathrm{V} 9-1^{3}$ & 9.5 & 9.5 & - & 6 \\
\hline $\mathrm{V} 8+\mathrm{V} 9-2^{3}$ & 9.5 & 9.5 & - & 6.5 \\
\hline$V 8+V 9-3^{3}$ & 9.5 & 9.5 & - & 6.5 \\
\hline$V 8+V 9-4^{3}$ & 8 & 8 & - & 7.5 \\
\hline Mean & 9.13 & 9.13 & - & 6.63 \\
\hline Standard deviation & 0.65 & 0.65 & - & 0.54 \\
\hline
\end{tabular}

${ }^{1}$ Controls 1-3: no ray excised.

${ }^{2}$ V9 1-6: ray V9 excised.

${ }^{3} \mathrm{~V} 8+\mathrm{V} 9$ 1-4: rays V8 and V9 excised. also generally occurs during regeneration of $\mathrm{D} 9$ in the sword (Fig. 5B). These results suggest that nonsword rays, when flanking the longest sword ray, can be induced to regenerate toward a final length typical of their new position, just like they are when an inducing sword ray is transplanted into their proximity.

Table 2. Number of segments in sword rays of juvenile fish after 5 weeks of testosterone treatment in the absence of ray $\mathrm{VB}$, or rays $\mathrm{V8}$ and $\mathrm{V9}$

\begin{tabular}{lcccc}
\hline & Ray V7d & Ray V7v & Ray V8 & Ray V10 \\
\hline Control 1 $^{1}$ & 30 & 40 & 53 & 39 \\
Control 2 $^{1}$ & 32 & 35 & 41 & 34 \\
Control 3 $^{1}$ & 30 & 32 & 55 & 30 \\
Mean & 30.67 & 35.67 & 49.67 & 34.33 \\
Standard deviation & 1.15 & 4.04 & 7.57 & 4.51 \\
V9-1 $^{2}$ & 32 & 32 & 44 & 27 \\
V9-2 $^{2}$ & 31 & 31 & 42 & 26 \\
V9-3 $^{2}$ & 40 & 41 & 52 & 25 \\
V9-4 $^{2}$ & 34 & 35 & 44 & 29 \\
V9-5 $^{2}$ & 31 & 31 & 40 & 19 \\
V9-6 & 32 & 32 & 38 & 15 \\
Mean & 33.33 & 33.67 & 43.33 & 23.50 \\
Standard deviation & 3.44 & 3.88 & 4.84 & 5.36 \\
V8+V9-1 & 33 & 32 & - & 18 \\
V8+V9-2 $^{3}$ & 23 & 23 & - & 23 \\
V8+V9-3 & 34 & 34 & - & 19 \\
Mean & 30.00 & 29.67 & - & 20.00 \\
Standard deviation & 6.08 & 5.86 & - & 2.65 \\
\hline
\end{tabular}

${ }^{1}$ Controls 1-3: no ray excised.

${ }^{2}$ V9 1-6: ray V9 excised.

${ }^{3} \mathrm{~V} 8+\mathrm{V} 9$ 1-3: rays V8 and V9 excised. 

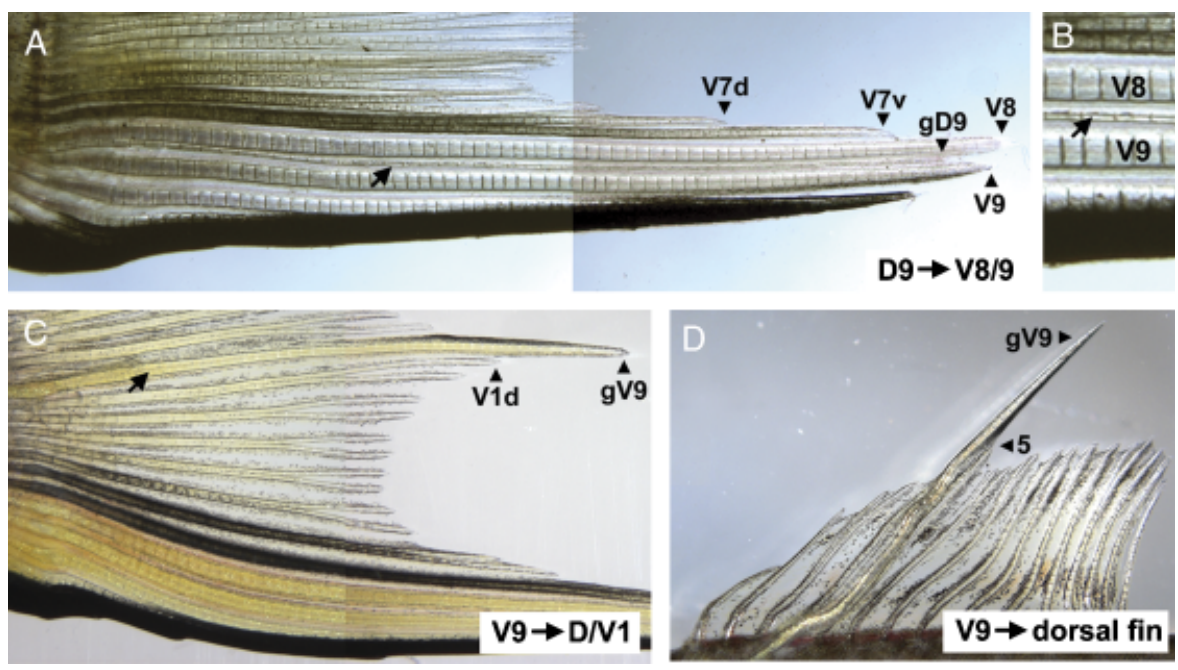

Fig. 5. Autotransplantation of caudal rays within unpaired fins. (A, B) Graft of ray $\mathrm{D} 9(\mathrm{gD} 9)$ into the sword, between V8 and V9. Arrows mark the grafted ray, arrowheads point to distal tips of rays or their branches; the grafted ray regenerates with narrower hemisegments (B), yet matches the length of the sword. (C) Transplant of sword ray $\mathrm{V} 9(\mathrm{gV} 9)$ into the medial caudal fin, between D1 and V1. Arrow marks the grafted ray at 2 months after transplantation, arrowheads point to distal tips of rays or their branches. (D) Transplant of sword ray V9 (gV9) into the dorsal fin, between the 4th and 5th ray; growth is induced in adjacent dorsal ray 5 , when the graft is fully integrated in the host fin. Arrowheads point to distal tips of rays.

\section{Fin rays differ in their response to the sword inducing signal}

To determine whether the ability to respond to the swordinducing signal is influenced by the position of flanking rays within the caudal fin, V9 was transplanted into the medial region, between D1 and V1 (Fig. 1D). As in dorsal grafts, V9 regenerated according to its original position $(n=3)$ i.e., it retained its yellow pigmentation, overgrew flanking rays, and the occurrence of melanophores was restricted to the interray mesenchyme of the grafted ray. However, although increased outgrowth was induced in adjacent medial rays, growth of flanking rays was overall less strong than when compared with the response elicited by grafts to a dorsal position (Fig. 5C).

To examine whether fin rays in other unpaired fins respond to the sword-inducing signal, we transplanted V9 to a rostral position in the dorsal fin (Fig. 5D). Rostral fin rays are often found to be elongated in various teleost species, such as in the anal fin-derived gonopodium. In all cases, the transplanted ray exceeded the length of the flanking dorsal fin rays and maintained its characteristic pigmentation, including the sword-like accumulation of melanophores in the interray tissue of grafted ray V9 $(n=2)$. Induction of other fin rays was observed in one case, where a flanking ray slightly overgrew the dorsal rays (Fig. 5D).

The lack of an unambiguous, growth-inducing response from dorsal fin rays indicates that sword-organizing activity may depend on the position of inducing or responding rays. Likewise, induction in the medial caudal fin fails to result in a strong response when compared with the dorsal and ventral caudal fin rays. This suggests that the growth-inducing effect elicited by the juxtaposition of sword and nonsword ray are dependent on their position within the caudal fin and on the type of fin.

\section{DISCUSSION}

The sword in swordtail fish is a sexually selected trait that evolved from a swordless ancestor (Meyer 1997). Its evolution and development has been a subject of examination because it was brought to wider attention with the publication of Darwin's "The Descent of Man and Selection in Relation to Sex" (Darwin 1871). To uncover how the sword develops is an important step toward understanding the developmental basis of the evolution of this sexually selected trait. Our transplantation and excision experiments suggest that previously unrecognized, inductive signals originate in the two longest sword rays, V8 and V9, that act to stimulate growth of adjacent fin rays during the development of the sword.

\section{Signals that originate in ventral fin rays V8 and V9 induce growth in flanking rays}

Both the transplantation and extirpation experiments show that V9 induces outgrowth in adjacent fin rays. Extirpation of V8 increases the effects of loss of V9, suggesting that both rays constitute an organizer complex, or sword organizer, a source of signals that during sword development induces growth in flanking fin rays and incorporates them into the growing sword.

In the developing sword, the organizer induces growth of the ventral black fin rays V7 and V10, whose length declines with increased distance to the organizer complex. This phenotype is most apparent in the sister branches of V7, in which the ventral one is the longer of both, suggesting the existence of a graded growth-stimulating signal. The extirpation experiments show that the reduction in growth rates of the smaller sword rays V7 and V10 is more pronounced when both long sword rays are removed, instead of V9 alone: The length of 
V10 is reduced by overall 10 segments when its neighbor V9 is extirpated, and is reduced by another three to four segments when V9 and V8 are missing. Similarly, the branches of ray V7 differ in length by on average five segments in sworded animals, with the ventral branch that flanks V8 being the longer one; again, extirpation of $\mathrm{V} 8$ and $\mathrm{V} 9$ reduces the length of the ventral branch even more than removal of V9 alone (Fig. 4A). We conclude that the sword-organizing signal from V8 and V9 acts over a distance of at least two fin rays. Both rays possess similar levels of signaling activity and transplantation of either alone results in swords that regularly regenerate to a shorter length than the genuine sword. This suggests that signaling within the sword organizer may positively feed back on itself.

The potential to form a sword is strongest in the upper and lower lobes of the caudal fin, but is reduced in its central part and in the dorsal fin. To account for these differences, our results support a model in which the ability to respond to the inductive signal may be differentially distributed. However, we cannot reject the alternative possibility that a strong inducing signal might not be supported in the medial caudal fin, even though all rays are similarly competent to respond to the sword organizer.

Our experiments and the finding that artificial exposure of female $X$. helleri to testosterone can also induce a swordlike extension from dorsal caudal fin rays (Dzwillo 1962, 1964), indicate a general competence of the outer rays of the caudal fin to respond to increased testosterone levels and suggests that these rays may be predisposed for sword development.

\section{Fin rays are subject to both ray-autonomous and nonray-autonomous signaling events}

Interactions between fin rays have previously been suggested to regulate regenerative growth in the zebrafish caudal fin, where the shorter medial rays regenerate additional segments if flanked by longer rays of the dorsal or ventral lobe, and finally approximate the length typical for the new position (Murciano et al. 2002). Moreover, probably the clearest case of interactions between fin rays has been demonstrated by Turner (1941), who studied the regeneration of gonopodial rays in the Mosquitofish, Gambusia affinis, after extraction of single rays. Differentiated rays of the 3-4-5 ray complex are characterized by combinations of bony terminal segments that form spines, plates, serrae, and hooks. When single rays of the 3-4-5 ray complex are systematically excised in immature fish, growth and differentiation of the remaining rays is affected. The development of a hook in ray 5 is thought to be dependent on signals from ray 4: extirpation of ray 5 , before gonopodial differentiation, results in the development of an ectopic hook in ray 6 , which now flanks ray 4 as its new dorsal neighbor. This ray 4-derived signal has been shown to trigger hook development in its dorsal neighbor, but it is not required for the progression of the differentiation process, which proceeds autonomously after a late extraction of ray 4 (Turner 1941). Moreover, the flanking nongonopodial rays 2 and 6 do seem to receive an inhibitory signal from the 3-4-5 ray complex, as they develop slightly more segments when their immediate neighbors have been removed. Thus, in contrast to gonopodial rays, which mainly control the fate of terminal lepidotrichs in neighboring rays, the long sword rays in $X$. helleri promote extended growth and regeneration in their neighbors.

Single grafts of both V8 and V9 overgrow their flanking rays and maintain their yellow coloration, indicating that regeneration occurs in a fin-ray autonomous manner and in accordance with their origin. Growth of gonopodial rays in G. affinis also appears to be regulated primarily through rayautonomous mechanisms, because in the absence of either one of the gonopodial rays the remaining rays grow to their expected length (Turner 1941). Further autonomous features of fin ray regeneration have been observed for single fin rays and for entire fins. When, in zebrafish, the first dorsal unbifurcated ray is grafted into the shorter interray region between the central-most rays, the transplanted ray retains its typical pigmentation type, although it fails to reach its original size (Murciano et al. 2002). Similarly, single fin rays that regenerate either in isolation from neighboring rays or are artificially exposed to the neighborhood of shorter rays, overall develop both a normal morphology and segment number in zebrafish and goldfish, implying autonomy with respect to their growth rate (Nabrit 1929; Mari-Beffa et al. 1999). Finally, Kallman and Gordon (1957) had used differently pigmented, highly inbred strains of $X$. maculatus to transplant dorsal or anal fins into the ventral myotome of the caudal peduncle. By examining host contribution during transplant regeneration based on its pigmentation pattern, whole fins were shown to regenerate according to their original identity. Taken together, these findings suggest that growth and differentiation of fins is controlled by signals that act both within individual rays and between adjacent fin rays.

\section{Growth and black pigmentation are independent traits of the sword}

Two types of experiments provide evidence that growth and black pigmentation of the sword are independent characters. First, removal of V8 and V9 in immature juveniles, followed by testosterone treatment, does result in a partial melanophore pattern typical for the sword, covering rays $\mathrm{V} 6$ and $\mathrm{V} 7$, even though $\mathrm{V} 7$ does not grow beyond the normal size of the fin (Fig. 4, C and D). Second, grafts of V8 into the dorsal caudal fin do induce growth in flanking rays, but ultimately fail to induce a sword-like pattern of melanophores around them, even though in its normal position V8 flanks the 
pigmented ray V7. Interestingly, although V9 does not seem to be required for the normal black pigmentation of the sword, dorsal grafts of V9 recurrently accumulate melanophores in their interray mesenchyme flanking the host rays and at their distal tips. Given enough time, also marginal flanking rays become covered with melanophores, such that the pigmentation pattern of the ectopic sword corresponds to the overall appearance of the genuine sword (Fig. 2A). When treated with testosterone, the $X$. helleri strain used in these experiments exhibits a propensity to form a black stripe at the dorsal margin of the caudal fin, quite similar to the dark vertical stripe on the ventral side (Fig. 3I). V9 may have acted to re-inforce this tendency both in its natural position in the sword and in dorsal grafts.

Like all transplanted rays, V7 is capable of autonomously regenerating its original pigmentation pattern in an ectopic position, as had been shown for whole grafted fins that regenerate from stumps in ectopic positions (Kallman and Gordon 1957). In this context, the mechanism proposed for this process in zebrafish, where new melanophores develop in the regenerating fin from putative stem cells (Rawls and Johnson 2000, 2001), might also be applicable to the regeneration of chromatophores in $X$. helleri. Because grafts of V7 fail to induce a pattern of melanophores in flanking rays, our findings suggest that the dorsal and ventral black stripes that outline the sword are generated by different mechanisms: while melanophores form on V7, and possibly on V6, in an autonomous way, the pattern on the ventral margin of the sword may be induced in part by signals emanating from V9. That the ventral black stripe consists of melanophores also descended from V9 itself is further supported by the formation of a single distal black interray margin in grafts of $\mathrm{V} 9$ to the dorsal fin and the center of the caudal fin (Figs. 2, C,D and 5C). In zebrafish, interactions between xanthophores and melanophores have been shown to be required to induce and maintain the organization of melanophores into stripes (reviewed in Parichy 2006, 2007). Further work is needed to address the possibility that similar interactions take place between these chromatophore populations of the long sword rays and the flanking black stripes, respectively.

\section{Developmental changes in sword evolution}

We propose a model for the evolution of the sword, in which the caudal rays V8 and V9 acquired a robust signaling mechanism that regulates their own growth in a ray-autonomous fashion, and that of flanking rays through a nonautonomous signaling component that serves to incorporate flanking rays into the proliferating sword. In extant swordtails this mechanism is established in embryonic or early larval development and is activated by androgen-mediated signaling in adult animals.
It is possible that this sword-inducing mechanism might have evolved through co-option of signaling pathways already present in gonopodial rays. Several observations would support this notion: the sword and the gonopodial 3-4-5 ray complex are formed by a similar set of rays, including the two ventral-most bifurcated fin rays and one (gonopodium) or two (sword) flanking unbifurcated rays, which furthermore share strong expression of the $m s x C$ gene during development and regeneration (Zauner et al. 2003). Finally, as in the long sword rays, the 3-4-5 ray complex in the evolutionarily older gonopodium (Meyer and Lydeard 1993; Zauner et al. 2003) possesses a robust, testosterone-dependent signaling system with a strong autoinductive component, in which the loss of one gonopodial ray does not significantly impair the growth of the others (Turner 1941). Similarly, the inactivation of this mechanism in an ancestor of the platyfish may have resulted in the loss of the sword, assuming a phylogeny of the genus in which the sword is ancestral (Meyer et al. 1994, 2006). As some platyfish have retained the ability to respond to artificial exposure to testosterone by developing a sword-like caudal fin extension (Gordon et al. 1943; Cohen 1946; Dzwillo 1962, 1964; Zander and Dzwillo 1969), one likely mechanism of sword-loss is a reduced response of the sword-inducing signaling pathway to testosterone.

This hypothesis could be tested by performing xenografts (between different species) between ventral caudal fins of $X$. helleri and a platyfish species that does not grow a sword under testosterone exposure. For example, if a platy graft into the regenerating sword were recruited into the sword, it could be followed that platies have retained the competence to react to the inducer, although they lost the ability to activate it in the presence of testosterone. Unfortunately, such experiments seem to be unfeasible, as xenografts and even allografts (within the same species) are rejected in the genus (personal observation; Held 1950; Kallman and Gordon 1957).

While the molecular identity of the sword-inducing signal is unknown, recent studies in regenerating zebrafish fins have linked the Fgf and $\mathrm{Wnt} / \beta$-catenin signaling pathways to fin regeneration (Poss et al. 2000a, b; Lee et al. 2005; Whitehead et al. 2005; Stoick-Cooper et al. 2007). Although not all of the molecules identified seem to be required for normal growth of fin rays, secreted signaling molecules are reasonable candidates for the elusive sword-inducer. Future studies will be required to identify these molecules, in order to study their regulation as well as the response to them, in a phylogenetic framework of swordtails and platyfish.

\section{Acknowledgments}

We would like to thank Manuel Mari-Beffa for introducing us to the transplantations protocol and Hans Zauner for successfully pioneering the technique in swordtails. We thank Nils Offen and members of the laboratory for comments on the script, and thank Janine Sieling for animal care. This work was funded by the Deutsche Forschungsgemeinschaft (DFG grant number BE 1902/4-1). 


\section{REFERENCES}

Akimenko, M. A., Mari-Beffa, M., Becerra, J., and Geraudie, J. 2003. Old questions, new tools, and some answers to the mystery of fin regeneration. Dev. Dyn. 226: 190-201.

Basolo, A. L. 1990a. Female preference for male sword length in the green swordtail, Xiphophorus helleri (Pisces: Poeciliidae). Anim. Behav. 40: 332-338.

Basolo, A. L. 1990b. Female preference predates the evolution of the sword in swordtail fish. Science 250: 808-810.

Basolo, A. L. 1991. Male swords and female preferences: response. Science 253: $1426-1427$.

Basolo, A. L. 1995a. A further examination of a pre-existing bias favouring a sword in the genus Xiphophorus. Anim. Behav. 50: 365-375.

Basolo, A. L. 1995b. Phylogenetic evidence for the role of a pre-existing bias in sexual selection. Proc. R. Soc. Lond. B Biol. Sci. 259: 307-311.

Basolo, A. L., and Alcaraz, G. 2003. The turn of the sword: length increases male swimming costs in swordtails. Proc. R. Soc. Lond. B Biol. Sci. 270: $1631-1636$

Cohen, H. 1946. Effects of sex hormones on the development of Platypoecilius maculatus. Zoologica 31: 121-128.

Darwin, C. 1871. The Descent of Man and Selection in Relation to Sex. John Murray, London.

Dzwillo, M. 1962. Einfluss von Methyltestosteron auf die Aktivierung sekundärer Geschlechtsmerkmale über den arttypischen Zustand hinaus (Untersuchungen an xiphophorinen Zahnkarpfen). Verh Dtsch Zool Ges Wien 56: $151-159$

Dzwillo, M. 1964. Sekundäre Geschlechtsmerkmale einiger Xiphophorini unter dem Einfluss von Methyltestosteron. Mitt. Hamburg. Zool. Mus. Inst. Kosswig-Festschrift 8: 15-22.

Endler, J. A. 1992. Signals, signal conditions, and the direction of evolution. Am. Nat. 139: S125-S153.

Gordon, M., Cohen, H., and Nigrelli, R. F. 1943. A hormone-produced taxonomic character in Platypoecilius maculatus diagnostic of wild P. xiphidium. Am. Nat. 77: 569-572.

Gordon, M., and Rosen, D. E. 1951. Genetics of species differences in the morphology of the male genitalia of xiphophorin fishes. Bull. Am. Mus. Nat. Hist. 95: 409-464.

Held, E. 1950. Experimental Studies of the Morphogenesis of the Gonopodium in Platypoecilius maculatus and Xiphophorus helleri. Thesis. University of California, Los Angeles, CA, 1-51.

Kallman, K. D., and Gordon, M. 1957. Transplantation of fins in Xiphophorin fishes. Ann. NY Acad. Sci. 71: 305-320.

Kallman, K. D., and Kazianis, S. 2006. The Genus Xiphophorus in Mexico and Central America. Zebrafish 3: 271-285.

Kirkpatrick, M., and Ryan, M. J. 1991. The evolution of mating preferences and the paradox of the lek. Nature 350: 33-38.

Langer, W. 1913. Beiträge zur Morphologie der viviparen Cyprinodontiden. In Gegenbaur's Morphologisches Jahrbuch. Vol. 47. Leipzig; Berlin: Engelmann: pp. 193-307.

Lee, Y., Grill, S., Sanchez, A., Murphy-Ryan, M., and Poss, K. D. 2005. Fgf signaling instructs position-dependent growth rate during zebrafish fin regeneration. Development 132: 5173-5183.

Mari-Beffa, M., Palmqvist, P., Marin-Giron, F., Montes, G., and Becerra, J. 1999. Morphometric study of the regeneration of individual rays in teleost tail fins. J. Anat. 195: 393-405.
Meyer, A. 1997. The evolution of sexually selected traits in male swordtail fishes (Xiphophorus: Poeciliidae). Heredity 79: 329-337.

Meyer, A., and Lydeard, C. 1993. The evolution of copulatory organs, internal fertilization, placentae and viviparity in killifishes (Cyprinodontiformes) inferred from a DNA phylogeny of the tyrosinase kinase gene X-src. Proc. R. Soc. Lond. B Biol. Sci. 254: 153-162.

Meyer, A., Morrissey, J. M., and Schartl, M. 1994. Recurrent origin of a sexually selected trait in Xiphophorus fishes inferred from a molecular phylogeny. Nature 368: 539-542.

Meyer, A., Salzburger, W., and Schartl, M. 2006. Hybrid origin of a swordtail species (Teleostei: Xiphophorus clemenciae) driven by sexual selection. Mol. Ecol. 15: 721-730.

Murciano, C., et al. 2002. Ray-interray interactions during fin regeneration of Danio rerio. Dev. Biol. 252: 214-224.

Nabrit, S. M. 1929. The role of the fin rays in the regeneration in the tailfins of fishes. Biol. Bull. 56: 235-266.

Parichy, D. 2006. Evolution of danio pigment pattern development. $\mathrm{He}$ redity 97: 200-210.

Parichy, D. 2007. Homology and the evolution of novelty during Danio adult pigment pattern development. J. Exp. Zool. B Mol. Dev. Evol. 308: 578-590.

Poss, K. D., Shen, J., and Keating, M. T. 2000a. Induction of lefl during zebrafish fin regeneration. Dev. Dyn. 219: 282-286.

Poss, K. D., et al. 2000b. Roles for FGF signaling during zebrafish fin regeneration. Dev. Biol. 222: 347-358.

Rawls, J. F., and Johnson, S. L. 2000. Zebrafish kit mutation reveals primary and secondary regulation of melanocyte development during fin stripe regeneration. Development 127: 3715-3724.

Rawls, J. F., and Johnson, S. L. 2001. Requirements for the kit receptor tyrosine kinase during regeneration of zebrafish fin melanocytes. Development 128: 1943-1949.

Rosenthal, G. G., and Evans, C. S. 1998. Female preference for swords in Xiphophorus helleri reflects a bias for large apparent size. Proc. Natl. Acad. Sci. USA 95: 4431-4436.

Rosenthal, G. G., Martinez, T. Y. F., De Leon, F. J. G., and Ryan, M. J. 2001. Shared preferences by predators and females for male ornaments in swordtails. Am. Nat. 158: 146-154.

Stoick-Cooper, C. L., et al. 2007. Distinct Wnt signaling pathways have opposing roles in appendage regeneration. Development 134 479-489.

Turner, C. 1941. Regeneration of the gonopodium of Gambusia during morphogenesis. J. Exp. Zool. 87: 181-210.

Whitehead, G. G., Makino, S., Lien, C.-L., and Keating, M. T. 2005. $f g f 20$ is essential for initiating zebrafish fin regeneration. Science 310 1957-1960.

Wiens, J. J., and Morris, M. R. 1996. Character definitions, sexual selection, and the evolution of swordtails. Am. Nat. 147: 866-869.

Zander, C. D., and Dzwillo, M. 1969. Untersuchungen zur Entwicklung und Vererbung des Caudalfortsatzes der Xiphophorus-Arten(Pisces). Z Wiss Zool 178: 275-315.

Zauner, H., Begemann, G., Mari-Beffa, M., and Meyer, A. 2003. Differential regulation of $m s x$ genes in the development of the gonopodium, an intromittent organ, and of the "sword," a sexually selected trait of swordtail fishes (Xiphophorus). Evol. Dev. 5: $466-477$ 